\title{
Análise Microbiológica de Barras de Cereais Elaboradas com Resíduos Industriais de Frutas
}

\author{
Elisabeth Mariano Batista (I), Rejane Maria Maia Moisés (I), Pahlevi \\ Augusto de Souza (I), Denise Josino Soares (I), Zulene Lima de \\ Oliveira (I), Monique Ellen Torres da Silva (I), Francisco Jorge \\ Nogueira de Moura (I), Auriana de Assis Regis (I), Hirllen Nara \\ Bessa Rodrigues Bezerra (I), Poliana Brito de Sousa (I) \\ (I) IFCE - Instituto Federal de Educação, Ciência e Tecnologia do Ceará (Rua: Estevam \\ Remígio, 1145, Centro, Limoeiro do Norte, Ceará, CEP 62930-000.), (II) IFCE - Instituto \\ Federal de Educação, Ciência e Tecnologia do Ceará (Rua: Estevam Remígio, 1145, Centro, \\ Limoeiro do Norte, Ceará, CEP 62930-000.)
}

\section{Resumo}

O desperdício de alimentos ocorre desde o início da cadeia produtiva e persiste durante as etapas de produção até chegar ao destino final. Uma maneira de combater o desperdício é o aproveitamento integral de frutas e hortaliças, por meio da utilização de partes não convencionais antes desprezadas, na elaboração de novos produtos como barras de cereais. As barras de cereais são constituídas pela mistura de ingredientes secos e de agente ligante e podem ser adicionadas de outros ingredientes como os resíduos agroindustriais. Tendo em vista que os resíduos de acerola e de caju não são aproveitados como fonte nutricional para alimentação humana, objetivou-se com o presente trabalho elaborar e avaliar o perfil microbiológico de barras de cereais elaboradas com resíduos destes frutos. Os resíduos de acerola e de caju foram adquiridos em indústrias de processamento de polpa de frutas. Estes foram desidratados, triturados e armazenados em embalagem de vidro previamente esterilizada a $100^{\circ} \mathrm{C}$ durante 30 minutos. Foram desenvolvidas quatro formulações diferentes de barras de cereais, variando o percentual de farinha de resíduo de fruta adicionado, sendo: A (0\%); B (10\%: $8 \%$ de farinha do resíduo de acerola e

\footnotetext{
Referência:

Elisabeth Mariano Batista, Rejane Maria Maia Moisés, Pahlevi Augusto de Souza, Denise Josino Soares, Zulene Lima de Oliveira, Monique Ellen Torres da Silva, Francisco Jorge Nogueira de Moura, Auriana de Assis Regis, Hirllen Nara Bessa Rodrigues Bezerra, Poliana Brito de Sousa. Análise Microbiológica de Barras de Cereais Elaboradas com Resíduos Industriais de Frutas. In: Anais do 12 Congresso Latinoamericano de Microbiologia e Higiene de Alimentos - MICROAL 2014 [= Blucher Food Science Proceedings, num.1, vol.1]. São Paulo: Editora Blucher, 2014.

DOI 10.5151/foodsci-microal-193
} 
2\% de farinha do resíduo de caju); C (15\%: $12 \%$ de farinha do resíduo de acerola e 3\% de farinha do resíduo de caju) e D (20\%: $16 \%$ de farinha do resíduo de acerola e $4 \%$ de farinha do resíduo de caju). Realizou-se a determinação do Número Mais Provável (NMP/g) de Coliformes totais, detecção de Salmonella sp. em 25g, contagem em placa de Aeróbios mesófilos (UFC/g) e Bolores e Leveduras (UFC/g). Todas as formulações apontaram contagem mínima de Salmonella sp. em $25 \mathrm{~g}$ das amostras. Quanto à contagem de aeróbios mesófilos, os quantitativos obtidos para as

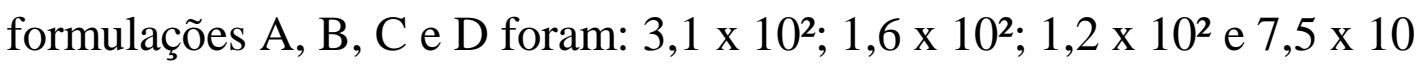
UFC/g e na avaliação de bolores e leveduras, 3,5 x 10;3,5 x 10;1,0 x 10 e $1,5 \times 10 \mathrm{UFC} / \mathrm{g}$, respectivamente. Os resultados obtidos nas análises microbiológicas das quatro formulações encontraram-se dentro dos padrões microbiológicos estabelecidos pela legislação vigente, apresentando-se portanto, seguras do ponto de vista microbiológico.

Palavras-Chave: acerola, aproveitamento, caju, desperdício, processamento Agência de Fomento: 